\title{
Prospective evaluation of patients readmitted after cardiac surgery: Analysis of outcomes and identification of risk factors
}

\author{
Hersh S. Maniar, MD, Jennifer M. Bell, BSN, Marc R. Moon, MD, Bryan F. Meyers, MD, \\ JoAnn Marsala, BSN, Jennifer S. Lawton, MD, and Ralph J. Damiano, Jr, MD
}

Objective: Reducing hospital readmissions after adult cardiac surgery is necessary as part of the solution to achieving improved efficiency in health care. Patients who had undergone cardiac surgery were studied to develop strategies that may diminish the need for hospital readmission.

\begin{abstract}
Methods: Over a 25-month period, 2096 patients underwent cardiac surgical procedures; 102 of these patients required readmission within 30 days of discharge. Time-matched patients $(n=249)$, not readmitted, served as a control group. Patient demographics and perioperative variables were analyzed by univariate analyses. Logistic regression analysis identified independent risk factors for readmission.
\end{abstract}

Results: The most common diagnoses given for readmission were congestive heart failure (26 of 102, 25\%), infection (23 of 102, 23\%), and arrhythmias (15 of 102, 15\%). The comorbidities more prevalent among readmitted patients were diminished ejection fraction $(44 \% \pm 17 \%$ vs $56 \% \pm 13 \% ; P<.0001)$, chronic obstructive pulmonary disease ( 23 of $102,23 \%$ vs 23 of $249,9 \% ; P=.0008$ ) and chronic renal insufficiency ( 26 of $102,26 \%$ vs 24 of $249,10 \% ; P=.0001$ ). Multivariate logistic regression identified chronic obstructive pulmonary disease (odds ratio [OR], $2.0 ; P=.05$ ), diminished ejection fraction (OR, $0.8 ; P<.0001$ ), a lower education level (OR, $0.5 ; P=.0001)$, and a prolonged length of stay (OR, 1.6; $P=.009)$ as predictive of readmission. Failure to see a physician early in the postoperative period was associated with a 6 -fold increase in the risk of readmission $(P<.0001)$.

Conclusions: Patients readmitted after cardiac surgery have specific comorbidities and are of lower socioeconomic status. They are admitted most commonly for exacerbation of congestive heart failure or infectious reasons. This study suggests that seeing a physician early after discharge may have an impact on reducing readmissions after cardiac surgery. (J Thorac Cardiovasc Surg 2014;147:1013-20)

Reducing hospital readmissions has been targeted by Medicare as a top strategic priority in an effort to improve patient care and decrease health dollar expenditures. ${ }^{1}$ The rate of unplanned rehospitalizations within 30 days of discharge among US Medicare patients has been estimated to be approximately $20 \%$ with associated costs of greater than $\$ 12$ billion per year. ${ }^{2}$ Although the legitimacy of hospital readmissions as a suitable marker for the quality of care provided by hospitals remains controversial, the recent passage of the Patient Protection and Affordable Care Act, which links hospital reimbursement to quality metrics such as the 30-day readmission rate, has placed

\footnotetext{
From the Division of Cardiothoracic Surgery, Department of Surgery, Washington University School of Medicine, St. Louis, Mo.

Disclosures: Authors have nothing to disclose with regard to commercial support.

Read at the 93rd Annual Meeting of The American Association for Thoracic Surgery, Minneapolis, Minnesota, May 4-8, 2013.

Received for publication May 6, 2013; revisions received Oct 13, 2013; accepted for publication Oct 26, 2013; available ahead of print Dec 23, 2013.

Address for reprints: Hersh S. Maniar, MD, Washington University School of Medicine, Cardiothoracic Surgery, Campus Box 8234, 660 S. Euclid Ave. St. Louis, MO 63110 (E-mail: faxmaniarh@wudosis.wustl.edu).

$0022-5223 / \$ 36.00$

Copyright (c) 2014 by The American Association for Thoracic Surgery

http://dx.doi.org/10.1016/j.jtcvs.2013.10.066
}

reducing readmissions at the forefront of most hospital administrations.

Initial efforts to reduce readmissions have targeted common medical conditions such as congestive heart failure (CHF), pneumonia, and acute myocardial infarction, but substantial interest has also developed in using a hospital's 30-day readmission rate as a metric for quality performance among patients undergoing surgical procedures. ${ }^{4-7}$ Cardiac surgery is likely to receive considerable attention because of the cost associated with its procedures and the high-risk patient population. ${ }^{8}$ However, less data are available regarding readmission after cardiac surgery and few reports use prospective data to address this issue. The purpose of this study was to prospectively identify risk factors for readmission for patients undergoing cardiac surgery.

\section{METHODS}

Between April 2011 and March 2013, 2096 patients underwent cardiac surgical procedures at a single tertiary care institution. The study group included patients who were readmitted to the hospital within 30 days of a cardiac procedure $(\mathrm{n}=102)$. Readmitted patients were identified as follows:

1. Using automated billing software that identified any patient admission to Barnes Jewish Hospital (BJH) within 30 days of a previous admission during which a cardiac surgical procedure was performed $(\mathrm{n}=70)$. 


\section{Abbreviations and Acronyms \\ $\mathrm{CHF}=$ congestive heart failure \\ $\mathrm{COPD}=$ chronic obstructive pulmonary disease \\ $\mathrm{EF}=$ ejection fraction \\ LVAD $=$ left ventricular assist device \\ STS $=$ Society of Thoracic Surgeons}

2. During routine outpatient follow-up when patients were queried on having been readmitted to an outside institution within 30 days of discharge $(\mathrm{n}=18)$.

3. As part of a random phone survey of 100 patients, conducted after discharge, when patients were queried directly about any postoperative admission after discharge $(\mathrm{n}=14)$.

No differences in baseline demographics were identified among readmitted patients identified by phone versus other methods (data not shown). The medical charts of all readmitted patients were prospectively reviewed by a cardiac surgeon (H.S.M.) and the primary reason for readmission was determined. Readmission diagnoses were grouped into 6 discrete categories: infectious, acute CHF, chronic CHF, arrhythmia, bleeding complication, and other.

The discharge process for patients on the cardiac surgical service during the study period was directed by a multidisciplinary team that included social workers, case managers, physical therapists, and nursing staff. Suitability for discharge was determined daily and patients were either deemed suitable for home discharge (with or without ancillary services) or to an extended care facility. Standards for discharge readiness were not different based on discharge location. Typically, patients were seen between 3 and 4 weeks after the date of discharge regardless of discharge location.

A control group of patients who were not readmitted was identified by randomly visiting all surgeons' office hours during the study period and identifying patients not readmitted within 30 days of discharge $(\mathrm{n}=163)$. No attempt was made to match control patients to study group patients. Patients also identified by the 100-patient random phone survey as not having been readmitted were included as part of the control group $(\mathrm{n}=86)$. Perioperative data for both groups were extracted from the Society of Thoracic Surgeons (STS) database and a patient questionnaire was prospectively administered to all patients with regard to non-STS variables (socioeconomic, medical compliance, physician providers) at either the time of readmission (for the readmitted group) or at the time of routine outpatient follow-up (control group).

The study was approved by the Washington University Human Research Protection Office and all patients provided informed consent for participation.

\section{Statistical Methods}

Comparisons were performed between patients who were readmitted $(n=102)$ and patients who were not readmitted $(n=249)$. The analyses of continuous variables were performed using $t$ tests except for cases where required conditions were not satisfied (and for ordinal variables); a Wilcoxon test was used as a nonparametric alternative. In general, between groups comparisons of categorical variables were analyzed by $\chi^{2}$ testing unless precluded by sample size, in which case a Fisher exact test was used. Statistically significant variables by univariate analysis $(P<.05)$ were considered for inclusion in stepwise multivariable logistic regression models predicting readmittance. The stepwise method selected variables for inclusion or exclusion from the model in a sequential manner based on the significance level of .10 for entry and .15 for removal. In cases of high intercorrelations of 0.70 or higher among some variables (ie, education and income levels), only a single measure was included. Adjusted odds ratios and associated $95 \%$ confidence intervals are reported for variables in the multivariable model, adjusted for all variables in the model. Two separate multivariate models were created to assess preoperative and perioperative characteristics associated with 30-day readmission. Data analysis was generated using SAS software, version 9.3 of the SAS System for Linux (SAS Institute Inc, Cary, NC).

\section{RESULTS}

The readmission rate approximated by the random phone survey was $14 \%$. Of all patients readmitted, $23 \%(n=23)$ were readmitted to an institution other than BJH. The most common readmission diagnoses were acute $\mathrm{CHF}(\mathrm{n}=12)$, chronic CHF $(\mathrm{n}=14)$, surgical site infection $(\mathrm{n}=11)$, other infection $(\mathrm{n}=12)$, arrhythmia $(\mathrm{n}=15)$, and bleeding complications $(\mathrm{n}=11)$. Seventy percent of all readmissions $(\mathrm{n}=71)$ occurred between days 0 and 15 after discharge (Figure 1). The median duration of a readmission hospitalization was 6 days (1-49 days), and 49\% $(n=50)$ of patients required a procedure during the readmission; the most common being chest tube insertion or thoracentesis $(\mathrm{n}=15)$, cardioversion or permanent pacemaker placement $(\mathrm{n}=9)$, or wound debridement $(\mathrm{n}=7)$. Three percent of patients $(\mathrm{n}=3)$ died during the readmission.

Univariate analysis identified the comorbidities of chronic obstructive pulmonary disease (COPD), chronic renal insufficiency, New York Heart Association class III or IV, peripheral vascular disease, and a lower ejection fraction (EF) as more prevalent among patients requiring readmission after surgery (Table 1). Similarly, readmitted patients reported lower annual incomes, were less likely to have more than high school education, or have established cardiology care preoperatively $(87 \%$ vs $94 \%$; $P=.03$ ) (Table 1).

Perioperative data (Table 2) demonstrated that readmitted patients were more likely to have undergone either cardiac transplantation $(n=2)$ or insertion of a left ventricular assist device (LVAD; $\mathrm{n}=16$ ), had a longer index hospital length of stay, and spent a greater number of hours being ventilated in the intensive care unit. No other differences were identified among the postoperative complications listed. Readmitted patients were more often discharged to a location other than home, more often prescribed warfarin but less likely to take their medications as prescribed (Table 3). In contrast, patients who were not readmitted were significantly more likely to have seen a physician early after discharge from the hospital compared with the study group.

The logistic regression models for preoperative and perioperative variables are shown in Table 4. By multivariate analysis, the presence of moderate or severe COPD or diminished EF were predictive of readmission. Similarly, a higher education or presence of an established cardiologist preoperatively remained protective of subsequent readmission. Perioperatively, the presence of a longer hospital length of stay or having been discharged to a location 


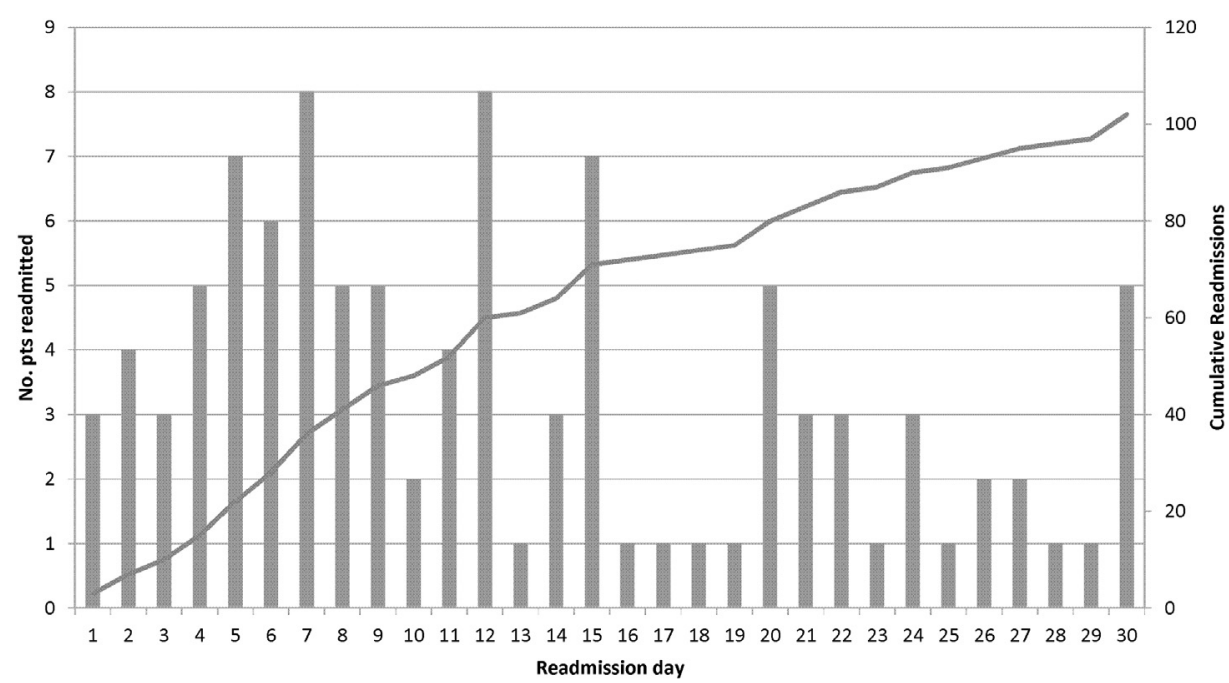

FIGURE 1. Days to readmission with cumulative readmissions noted. The solid line represents cumulative incidence of readmissions over the time period. Seventy percent of all readmissions $(n=71)$ occurred between days 0 to 15 after discharge.

other than home was predictive of readmission. Seeing a physician early after discharge, however, remained the most highly predictive statistic against hospital readmission.

\section{DISCUSSION}

This investigation resulted in 3 major findings. The first is that the most common reasons for readmission after any type of cardiac surgery were infection or exacerbation of CHF.

TABLE 1. Patient demographics

\begin{tabular}{|c|c|c|c|}
\hline & $\begin{array}{c}\text { Readmitted } \\
(\mathbf{N}=102)\end{array}$ & $\begin{array}{l}\text { Not readmitted } \\
\quad(\mathbf{N}=\mathbf{2 4 9}) \\
\end{array}$ & $P$ value \\
\hline Age (y) & $64 \pm 15$ & $63 \pm 14$ & .54 \\
\hline Female gender, n (\%) & $42(41)$ & $85(34)$ & .21 \\
\hline Diabetes, n (\%) & $42(41)$ & $86(35)$ & .24 \\
\hline Hypertension, n (\%) & $81(79)$ & $204(82)$ & .58 \\
\hline COPD, n (\%) & $23(23)$ & $23(9)$ & .0008 \\
\hline CRI, n (\%) & $26(25)$ & $24(10)$ & .0001 \\
\hline CVD, n (\%) & $25(25)$ & $52(21)$ & .46 \\
\hline NYHA III or IV, n (\%) & $69(67)$ & $112(45)$ & .0001 \\
\hline PVD & $38(37 \%)$ & $65(26 \%)$ & .04 \\
\hline BMI $\left(\mathrm{kg} / \mathrm{m}^{2}\right)$ & $29.6 \pm 6.7$ & $29.4 \pm 6.5$ & .76 \\
\hline Ejection fraction $(\%)$ & $44.3 \pm 17.8$ & $56 \pm 13.4$ & $<.0001$ \\
\hline Income, n (\%) & & & .009 \\
\hline$<\$ 50,000$ & $17(17)$ & $21(8)$ & \\
\hline$\$ 50,000-100,000$ & $85(83)$ & $222(89)$ & \\
\hline$>\$ 100,000$ & 0 & $6(2)$ & \\
\hline Education, n (\%) & & & $<.0001$ \\
\hline Less than high school & $32(31)$ & $37(15)$ & \\
\hline High school graduate & $53(52)$ & $118(47)$ & \\
\hline More than high school & $17(17)$ & $94(38)$ & \\
\hline
\end{tabular}

$\overline{C O P D}$, Moderate or severe chronic obstructive pulmonary disease; $C R I$, chronic renal insufficiency; $C V D$, cerebrovascular disease; NYHA, New York Heart Association Functional Classification; $P V D$, peripheral vascular disease; $B M I$, body mass index.
Although these findings are consistent with previous literature on readmission after coronary artery bypass grafting, this study also highlights the importance of particular patient subgroups such as those with COPD, a diminished EF or chronic renal insufficiency that may be predisposed or less tolerant of volume shifts and more likely to exacerbate CHF. ${ }^{6,-10}$ These findings suggest that by focusing on particular at-risk groups, rather than the adult surgical population as a whole, a patienttargeted approach may prove to be more successful in reducing readmissions compared with previous efforts. ${ }^{7-11}$ The significance of including all cardiac procedures within this investigation highlights the prevalence of CHF and infection as the primary predominant postoperative issues after any cardiac surgery. Although other studies have specifically excluded patients undergoing insertion of an LVAD from readmission surveys, the inclusion of these and other procedures with historically high readmission rates was considered appropriate because they represent an increasing proportion of adult cardiac surgeries at tertiary care centers where the performance of isolated CABG has become increasingly rare. ${ }^{12}$ Although of only borderline significance in this study, LVAD procedures represent a specific procedure-targeted group on which to concentrate efforts to reduce readmission. ${ }^{13}$

The second principal finding of this study was the significant association between socioeconomic and environmental factors and subsequent need for readmission after surgery. Patients with lower income and education levels or without established health care preoperatively were more likely to be readmitted postoperatively, independent of their comorbidities. Although the impact of socioeconomic factors has been demonstrated to an extent in other reports, few have incorporated these variables prospectively or have been able to quantify their role as independent risk 
TABLE 2. Perioperative data

\begin{tabular}{lccc}
\hline & $\begin{array}{c}\text { Readmitted } \\
(\mathbf{N}=\mathbf{1 0 2})\end{array}$ & $\begin{array}{c}\text { Not readmitted } \\
(\mathbf{N}=\mathbf{2 4 9})\end{array}$ & $\boldsymbol{P}$ value \\
\hline Operative type, n (\%) & & & .006 \\
$\quad$ Isolated CABG & $28(27)$ & $68(27)$ & \\
Isolated valve & $23(23)$ & $75(30)$ & \\
CABG/valve & $19(19)$ & $59(24)$ & \\
Aortic surgery & $8(8)$ & $13(5)$ & \\
Arrhythmia surgery & $1(1 \%)$ & $7(3)$ & \\
$\quad$ Transplant/VAD & $18(18)$ & $11(4)$ & \\
Surgery duration (h) & $4.8 \pm 1.7$ & $4.7 \pm 1.7$ & .65 \\
CPB duration (min) & $113 \pm 67$ & $116 \pm 64$ & .67 \\
Crossclamp time (min) & $89 \pm 39$ & $84 \pm 35$ & .56 \\
Total length of stay (d) & $12.6 \pm 7.6$ & $8.5 \pm 6.0$ & $<.0001$ \\
Ventilator time (h) & $28 \pm 36$ & $17 \pm 26$ & $<.0001$ \\
Reexploration, n (\%) & $5(5)$ & $4(2)$ & .13 \\
CVA, n (\%) & $3(3)$ & $5(2)$ & .70 \\
ARF requiring HD, n (\%) & $2(2)$ & $3(1)$ & .63 \\
IABP, n (\%) & $7(7)$ & $5(2)$ & .05 \\
Reintubation, n (\%) & $4(4)$ & $9(4)$ & 1.0 \\
Arrhythmia, n (\%) & $27(26)$ & $82(33)$ & .23 \\
\hline CABG, Coronary artery bypass grafting; $V A D$, ventricular assist device; $C P B$, cardio- \\
pulmonary bypass; $C V A$, cerebrovascular accident; $A R F$, acute renal failure; $H D$, \\
hemodialysis; IABP, intra-aortic balloon pump. & & \\
& & &
\end{tabular}

factors for readmission. ${ }^{5,6,14}$ Health care awareness is likely a combination of education, income, and medical compliance and, although this investigation assessed these variables individually, it was apparent that significant statistical intercorrelation existed among the 3 factors, thus allowing only for education to be included with multivariate modeling. Medical compliance in this series, although more common among patients who were not readmitted, may have been overestimated as a selfreported metric and the statistical power of this measure was limited as both groups reported greater than $90 \%$ compliance. Examples within the cardiovascular literature have demonstrated that as many as $50 \%$ of patients are unable to list their diagnoses or the details of the

TABLE 3. Discharge variables

\begin{tabular}{lccc}
\hline & $\begin{array}{c}\text { Readmitted } \\
(\mathbf{N}=\mathbf{1 0 2})\end{array}$ & $\begin{array}{c}\text { Not readmitted } \\
(\mathbf{N}=\mathbf{2 4 9})\end{array}$ & $\boldsymbol{P}$ value \\
\hline Discharge location, n (\%) & & & $<.0001$ \\
$\quad$ Extended care facility & $35(34)$ & $37(15)$ & \\
$\quad$ Home & $67(66)$ & $212(85)$ & \\
Discharge medications, n (\%) & & & \\
$\quad$ Aspirin & $92(90)$ & $226(91)$ & .87 \\
$\quad \beta$-Blocker & $68(67)$ & $178(71)$ & .37 \\
Warfarin & $41(40)$ & $63(25)$ & .006 \\
$\quad$ Diuretic & $84(82)$ & $191(77)$ & .24 \\
Medication compliance, n (\%) & $93(91)$ & $243(98)$ & .02 \\
Seen by doctor early after & $34(33)$ & $188(76)$ & $<.0001$ \\
$\quad$ discharge & & & \\
\hline Medication compliance means filling prescriptions and taking as directed. &
\end{tabular}

medications they were prescribed at the time of discharge, suggesting that the true rate of medical compliance among socioeconomically challenged patients is likely lower. ${ }^{5}$ This issue applies particularly to academic centers, most of which care for the medically indigent. Larger retrospective reviews have emphasized that it is exactly these centers that care for the socioeconomically disadvantaged that are likely to be most affected by penalties affixed to readmission metrics. ${ }^{3}$

The third finding of this investigation was the protective association for readmission conferred on patients who had seen a physician earlier than their scheduled postoperative visit at 3 to 4 weeks. Although the ability to see a physician postoperatively is potentially confounded by multiple factors including physician availability, socioeconomics, and patient illness, the strength of association between early postoperative visits and freedom from readmission demonstrated in this study deserves further study. Several studies have documented that early patient contact after discharge, even if by telephone within 48 hours, can improve outpatient follow-up, allay patient anxiety, and allow for medication adjustment and improved medication compliance. ${ }^{15-18}$ Although the estimates by the Medicare Payment Advisory Commission suggest that only $13 \%$ of hospital readmissions at 30 days are preventable, ${ }^{3}$ the interventions most likely to succeed are those performed within the first 1 to 2 weeks of hospital discharge, the period in which most readmissions seem to occur ${ }^{11,19}$ (Figure 1). In a recent pilot study involving home visits after cardiac surgery, it was demonstrated that follow-up within the first week of discharge decreased readmission due to infection and CHF by $25 \%$ through simple wound care, medication adjustment, patient reassurance, and use of occasional oral antibiotics. ${ }^{20}$

Whether extended care facilities can serving as surrogates for physician visits seems unlikely based on the high rate of readmission from these centers as seen in this investigation. Presumably the capabilities of a given extended care facility can vary, but the success of these facilities in managing patients likely depends more on the patient's need for ongoing organized care. ${ }^{19,21}$ Although extended care facilities are likely to succeed in caring for healthier patients admitted because of inadequate social support systems at home, patients in need of specialized care after discharge represent a sicker cohort and may still benefit from earlier physician visits. And although this investigation has highlighted certain comorbidities such as COPD, renal insufficiency, and decreased EF that aid in identifying particularly at-risk groups, it further suggests that the hospital length of stay of the index admission should be considered. Although length of stay is not a specific clinical entity, it is likely an excellent indicator of the complexity of a patient's postoperative course; and when prolonged, it represents a subgroup of patients who 
TABLE 4. Preoperative and postoperative logistic regression models

\begin{tabular}{|c|c|c|c|c|}
\hline Variable & $\begin{array}{l}\text { Odds } \\
\text { ratio }\end{array}$ & $\begin{array}{c}95 \% \\
\text { confidence } \\
\text { interval for } \\
\text { odds ratio } \\
\end{array}$ & $\begin{array}{c}\text { Incremental } \mathbf{r}^{2} \\
\text { (selection order) }\end{array}$ & $\begin{array}{c}P \\
\text { value } \\
\end{array}$ \\
\hline \multicolumn{5}{|l|}{ Preoperative } \\
\hline COPD & 2.00 & $0.98,4.06$ & $0.24(4)$ & .05 \\
\hline Ejection fraction $\%$ & 0.80 & $0.74,0.87$ & $0.15(1)$ & $<.0001$ \\
\hline Education level & 0.52 & $0.36,0.76$ & $0.21(2)$ & .0001 \\
\hline Previous cardiologist & 0.41 & $0.16,1.00$ & $0.22(3)$ & .03 \\
\hline \multicolumn{5}{|l|}{ Postoperative } \\
\hline $\begin{array}{l}\text { Transplant/VAD } \\
\text { procedure }\end{array}$ & 2.37 & $0.88,6.39$ & $0.31(4)$ & .09 \\
\hline Length of stay & 1.56 & $1.12,2.18$ & $0.28(2)$ & .009 \\
\hline $\begin{array}{r}\text { Discharge location } \\
\text { other than home }\end{array}$ & 2.09 & $1.11,3.92$ & $0.30(3)$ & .02 \\
\hline $\begin{array}{l}\text { Seen by doctor early } \\
\text { after discharge }\end{array}$ & 0.18 & $0.11,0.31$ & $0.21(1)$ & $<.0001$ \\
\hline
\end{tabular}

For ejection fraction, the odds ratio reflects the increased odds of undergoing readmittance for a $5 \%$ increase in ejection fraction. For education, the odds ratio reflects the increased odds of undergoing readmittance for each category increase in education. Length of stay reflects the increased odds of readmittance for a 1-increment increase in the length of stay category. Length of stay is categorized as follows: $<7$ days, 7-13 days, 14-20 days, $\geq 21$ days. COPD, Moderate or severe chronic obstructive pulmonary disease; $V A D$, ventricular assist device.

are most used to inpatient services and most likely to have the greatest difficulty adapting to the outpatient setting, predisposing to readmission..$^{9,22,23}$

\section{Limitations}

The readmission rate generated by the limited random sampling in this investigation, although consistent with other series, acknowledges the possibility of underestimation given the numbers of patients lost to follow-up or admitted elsewhere after discharge. ${ }^{6-9,24}$ Although this may underestimate the true readmission rate, it is less likely to affect the reasons why patients were readmitted. This single-center experience was limited by sample size, precluding the use of more sophisticated matching between study patients and control patients, and required the use of 2 multivariate logistic regression models to allow for testing of statistically and clinically significant covariates identified by univariate algorithms. With greater sample size, better statistical modeling would be possible and the impact of comorbidities, socioeconomics, and perioperative data might then be assessed within a single model. Although a retrospective chart review of the index hospitalization for all readmitted patients was performed to determine if readmissions were preventable, the accuracy of such a review was intrinsically limited and not considered accurate for analysis. Although the impact of early physician visits is statistically valid, the possibility of confounding elements cannot be excluded in this study. An understanding of what interventions, if any, were performed at these visits would strengthen this association. Similarly early follow-up was defined only as before the scheduled follow-up that occurred between 3 and 4 weeks after discharge. Further study will ideally elaborate on the optimum time for these visits.

\section{CONCLUSIONS}

This investigation confirms the presence of a high readmission rate after cardiac surgery and is likely to be scrutinized by Centers for Medicare \& Medicaid Services in the near future. This study also suggests that the reasons for readmission are common, apply to almost all cardiac surgical procedures, and specific patient populations are particularly at risk for hospital readmission. From the data from this investigation, it can be hypothesized that early visitation after discharge to a physician in the outpatient setting may have a significant effect in reducing hospital readmission. Although the timing and exact mechanisms of early follow-up are less clear, efforts made within the first 2 weeks seem more likely to succeed because they focus on a critical period of vulnerability when readmissions are most common. ${ }^{8,14-17}$ Further investigation in a prospective intervention-based trial should be considered.

\section{References}

1. WHO Regional Office for Europe's Health Evidence Network (HEN). Do Current Discharge Arrangements from Inpatient Hospital Care for the Elderly Reduce Readmission Rates, the Length of Inpatient Stay or Mortality, or Improve Health Status? Geneva, Switzerland: World Health Organization; 2005.

2. Medicare Payment Advisory Commission. Report to Congress: Promoting Greater Efficiency I Medicate. Washington DC: Medicare Payment Advisory Commission; 2007.

3. Joynt KE, Jha AK. Thirty-day readmissions-truth and consequences. $N$ Engl J Med. 2012:366:1366-9.

4. McPhee JT, Nguyen LL, Ho KJ, Ozaki CK, Conte MS, Belkin M. Risk prediction of 30 day readmission after infrainguinal bypass for critical limb ischemia J Vasc Surg. 2013;57:1481-8.

5. Khawaja FJ, Shah ND, Lennon RJ, Slusser JP, Alkatib AA, Rihal CS, et al Factors associated with 30-day readmission rates after percutaneous coronary intervention. Arch Intern Med. 2012;172:112-7.

6. Li Z, Armstrong EJ, Parker JP, Danielsen B, Romano PS. Hospital variation in readmission after coronary artery bypass surgery in California. Circ Cardiovasc Qual Outcomes. 2012;5:729-37.

7. Iribarne A, Alexander JH, Ogara PT, Chang H, Gillinov MA, Moquete E, et al. Readmissions after cardiac surgery: experience of the NIH/CIHR Cardiothoracic Surgical Trials Network. Ann Thorac Surg. In press.

8. Price JD, Romeiser JL, Gnerre JM, Shroyer AL, Rosengart TK. Risk analysis for readmission after coronary artery bypass surgery: developing a strategy to reduce readmissions. J Am Coll Surg. 2013;216:412-9.

9. Hannan EL, Zhong Y, Lahey SJ, Culliford AT, Gold JP, Smith CR, et al. 30-Day readmissions after coronary artery bypass graft surgery in New York State JACC Cardiovasc Interv. 2011;4:570-6.

10. Hannan EL, Racz MJ, Walford G, Ryan TJ, Isom OW, Bennet E, et al. Predictors of readmission for complications of coronary artery bypass graft surgery in New York State. JAMA. 2003;290:773-80.

11. Burke RE, Coleman EA. Interventions to decrease hospital readmissions. JAMA Intern Med. 2013;173:695-8.

12. Forest SJ, Bellow R, Friedmann P, Casazza D, Nucci C, Shin JJ, et al. Readmissions after ventricular assist device: etiologies, patters, and days out of hospital. Ann Thorac Surg. 2013;95:1276-81.

13. Lee R, Homer N, Andrei AC, McGee EC, Malaisrie SC, Kansal, et al Early readmission for congestive heart failure predicts late mortality after cardiac surgery. J Thorac Cardiovasc Surg. 2012;144:671-6.

14. Arbaje AI, Wolff JL, Yu Q, Powe NR, Anderson GF, Boult C. Postdischarge environmental and socioeconomic factors and the likelihood of early hospital 
readmission among community-dwelling Medicare beneficiaries. Gerontologist. 2008;48:495-504.

15. Hansen LO, Young RS, Hinami K, Leung A, Williams MV. Interventions to reduce 30-day rehospitalization: a systematic review. Ann Inern Med. 2011; 155:520-8.

16. Costantino ME, Frey B, Hall B, Painter P. The influence of a postdischarge intervention on reducing hospital readmissions in a Medicare population. Popul Health Manag. 2013;16:310-6.

17. Anderson SL, Marrs JC, Vande Griend JP, Hanratty R. Implementation of a clinical pharmacy specialist-managed telephonic hospital discharge follow-up program in a patient-centered medical home. Popul Health Manag. 2013;16:1-7.

18. Hernandez AF, Greiner MA, Fonarow GC, Hammill BG, Heidenreich PA, Yancy CW, et al. Relationship between early physician follow-up and 20-day readmission among Medicare beneficiaries hospitalized for heart failure. JAMA. 2010;303:1716-22.

19. Dharmarajan K, Hsieh AF, Lin Z, Bueno H, Ross JS, Horwitz LI, et al. Diagnoses and timing of 30-day readmissions after hospitalization for heart failure, acute myocardial infarction or pneumonia. JAMA. 2013;309:355-63.

20. Nabagiez JP, Shariff MA, Khan MA, Molloy WJ, McGinn JT Jr. Physician assistant home visit program to reduce hospital readmissions. J Thorac Cardiovasc Surg. 2013;145:225-33.

21. Grigonis AM, Snyder LK, Dawson AM. Long-term acute care hospitals have low impact on Medicare readmissions to short-term acute care hospitals. Am J Med Qual. 2013.

22. Galas FR, Almeida JP, Fukushima JT, Oswawa EA, Nakamura RE, Silva CM, et al. Blood transfusion in cardiac surgery is a risk factor for increased hospital length of stay in adult patients. J Cardiothorac Surg. 2013;8:54.

23. Lee JD, Bonaros N, Hong PT, Kofler M, Srivastava M, Herr DL, et al. Factors influencing hospital length of stay after robotic totally endoscopic coronary artery bypass grafting. Ann Thorac Surg. 2013;95:813-8.

24. Moore L, Stelfox HT, Turgeon AF, Nathens AB, Sage NL, Emond M, et al. Rates, patterns and determinants of unplanned readmission after traumatic injury. Ann Surg. 2013.

\section{Discussion}

Dr Ani C. Anyanwu (New York, NY). The issue of hospital readmissions is certainly one that is important to all cardiothoracic surgeons all over the world because we are pressured to reduce readmissions but likewise to reduce the length of hospital stay. Finding a balance between the two is difficult because the shorter the hospital stay, the more likely there will be a rebound in higher readmission rates.

So in this study, Dr Maniar and colleagues have explored readmissions over a 2-year period and identified risk factors. There are, though, some limitations inherent in the study design.

Almost certainly the incidence of readmission has been grossly underestimated due to patients being readmitted to other institutions. Relying on self-reporting by patients is not an effective way of capturing readmissions elsewhere. This is demonstrated in their article, which you kindly sent me, in which you did a random sample of 100 patients by telephone and found $14 \%$ had, unknown to the research team, been readmitted in other hospitals.

Another limitation is the likelihood of the confounding effect of some of the variables you have studied. For example, the inference that seeing a physician earlier after discharge is beneficial in reducing hospital stay is not robust.

One-third of your patients were readmitted within 7 days of discharge, and it is very unlikely patients would see a doctor within the first 7 days of going home. Similarly, $34 \%$ of your readmitted patients were readmitted from an extended care facility, and patients in rehab facilities are also not likely to have gone to see their physician. Finally, some patients might not have seen their primary physician because they were too sick to do so because they were not feeling well, and it is this unwell state that triggered them being readmitted subsequently. So the presumed protective effect of seeing a physician could therefore be a confounding one, and the higher readmission rate of patients who did not see their physicians might just reflect sickness and comorbidity, rather than any factor that could have been prevented by the primary physician.

Presumably, too, some of their admissions were triggered by seeing a physician either in the office or emergency room, and then they were subsequently admitted; this is not commented on in your article. The authors do not provide any data showing how many readmissions would likely have been prevented if they had seen a doctor. I suspect it is the minority.

So the relationship between seeing a physician early after discharge and readmission can at this time not be regarded as a causative relationship and is something you would have to explore in the future.

Finally, the inclusion of ventricular assist device patients skews the data considerably given the high readmission rate in this patient cohort, in some series as high as $80 \%$. It would be helpful if you did a sensitivity analysis that excluded ventricular assist device patients to see whether your conclusions still hold.

I have four questions for the authors. First, do the authors have uniform discharge criteria, and what is your postoperative schedule for physician visits? As going to a rehab facility was a predictor of readmission, did your thresholds differ between discharge to rehab as opposed to discharge home; that is, were you sending patients home earlier to rehab than home?

Dr Maniar. In answer to your first question, our current practice has been modified as a result of this study; many patients are now seen 2 weeks after discharge by either surgeon or referring cardiologist. There has, furthermore, been some data suggesting that interventions such as a simple phone call made at the 48-hour or the 72-hour mark may be able to further reduce the number of readmissions seen in the first week. We have not yet adopted such a strategy but it is something for us to consider.

Dr Anyanwu. My second question, there is an obligatory readmission rate with any major surgical operation. Do you have a handle on what this rate should be, and did you do an analysis to ascertain how many of these readmissions were actually preventable, and did you identify mechanisms by which you could have prevented them?

Dr Maniar. Sure. It is a good question. I think if you look across the board and you extract data from the medical series, the estimated likelihood of an admission being preventable is estimated somewhere between $10 \%$ and $25 \%$ or so. We did not specifically categorize readmissions as preventable or not. However, it may be possible to reduce the number of patients, particularly with volume overload or minor wound issues, which are common reasons for readmission. The key is to identify the more at-risk populations for these common readmission reasons and focus on them.

Dr Anyanwu. My third question is regarding your relationship between lower income, lower education, noncompliance, and readmission.

I do find it hard to conclude from your data that these factors themselves are responsible for readmission, and indeed you just showed us that medical compliance in the readmission group was actually $91 \%$. Is it not more probable that these are confounding factors that reflect patients with more comorbid conditions and advanced disease? For 
example, smoking and lack of primary prevention measures would be more likely in the lower socioeconomic groups and would possibly independently predict readmission.

Most of your readmissions, as you say, were for medical reasons like infection, heart failure, arrhythmia, and bleeding. Did you actually demonstrate that lack of medical compliance contributed directly to any readmissions?

Dr Maniar. So it is a good question, and it brings up several points. The first is the reliance on patients telling you that they are medically compliant. That number is typically way overrepresented. I wouldn't necessarily dismiss the high compliance rate reported in this series but nor would I make too much of it.

The findings of the importance of socioeconomics in this study were a bit surprising, particularly with regard to income and education level. And despite trying to account for all of the confounding variables that we could find, the relationship between readmission and socioeconomics remained statistically robust. This is of course association and not causation by any means.

And similarly, seeing a physician seems to be associated with less readmissions. I think the next step will be some sort of prospective evaluation of an intervention, and it is likely that we will start with the higher at-risk patients, particularly those who are being discharged to an extended care facility. Apparently, of the $30 \%$ of our patients who were discharged to an extended care facility in this series, $20 \%$ ended up requiring readmission.

Dr Anyanwu. My final question is, how has your practice changed and what message should we take to our practices?

I would like to thank you for the privilege of discussing your paper.

Dr Maniar. Thank you. The change has been that I now see patients, as do many of my partners now, at the 2-week interval. Whether we adopt other interventions is something that needs to be discussed. The magic bullet may be targeting a specific patient population with a targeted intervention that will lead to increased medication compliance, allow for medication adjustment, and improve compliance with immediate outpatient visits.

Dr Glenn J. R. Whitman (Baltimore, Md). Dr Maniar, this is an extremely timely report. There is a similar study of patients in the eastern United States that looked at several thousand Medicare patients after heart surgery. Their discovery of causes of readmission mirrored yours.

The following, therefore, represent opportunities for improvement: congestive heart failure, for example, or arrhythmias. Did you look at patients in the CHF category, focusing on discharge weight compared with admission, or determining whether appropriate afterload reducers or diuretics were prescribed at discharge?

Or with arrhythmias, at least in our institution, we use amiodarone as well as $\beta$-blockers postoperatively. If they have not gone into atrial fibrillation, we stop the amiodarone as they are discharged, leaving the patient just on a $\beta$-blocker. Perhaps maintaining amiodarone for a longer period would decrease the admission rate for this category.

Now that you have a control population, you could, in fact, look at these two populations, one that was readmitted, one that was not, specifically looking at issues that might impact readmission for heart failure and arrhythmia. One could even look at the SCIP (surgical care improvement project) measures for wound infection prevention and see whether they were the same in the readmitted population versus the population not readmitted. This might give us insight into valuable methods for preventing readmissions in all 3 categories (heart failure, arrhythmias, and infections).

Dr Maniar. Thank you for your comment. My initial hypothesis was that patients who were being readmitted for heart failure were exactly that, discharged home at a higher weight than on admission, or maybe discharged home without appropriate use of diuretics. I was wrong on both counts. There was no difference between the two groups with respect to changes in weight or use of diuretics.

So it is more complex I think than weight and simple diuretics, because a lot of these patients have some degree of renal insufficiency in the immediate perioperative course that limits how aggressively diuretics can be used on an outpatient. Although we certainly already educate our patients regarding weight gain, perhaps we need to emphasize this more so that they call early when they see their weight going up as an outpatient.

With regards to atrial fibrillation, we looked at $\beta$-blocker use, which was the same in both groups. The increasing number of studies demonstrating the efficacy of prophylactic use of amiodarone does represent an opportunity to try to reduce postoperative arrhythmias. Although many of us do not feel that amiodarone may be safe long-term postoperatively, your strategy, which is you discontinue it at the time of discharge, may be a reasonable strategy. It is a growing area and certainly I think an area that is ripe for more investigation.

As for infection, it turns out that about $50 \%$ of infections are wound related and $50 \%$ are what I would call systemic. Reducing these admissions may be best targeted by ensuring best practices during the in-patient stay (ie, timing and duration of antibiotics along with appropriate skin preparation), and then perhaps some degree of improved wound care early in the postoperative period.

Dr Rakesh C. Arora (Winnipeg, Manitoba, Canada). Thank you for this very interesting talk, and I have a comment and a question regarding the last bullet point on your concluding slide with regard to needing a physician early after discharge.

At our institution we have a dedicated clinic that is run by a nurse practitioner; $100 \%$ of our patients are seen either directly in the clinic or, depending on geographic barriers, by phone. We find this to be very effective for optimization of medications, glycemic control for diabetic patients, anticoagulation issues, and identification of surgical-site infection that could be dealt in the community.

The purpose of this is to allow transition from the time of hospital discharge to the time when they see their community physician, and that may obviate the need to have a physician as part of that process as you have identified in the article.

The question I have is in regard to your content for your discharge planning. Is there perhaps something through your investigation that can be identified as a defect (ie, root cause of the problem) either in the amount or content of discharge instruction material that can be targeted for improvement for your patient population that will allow for better compliance and understanding of the need for compliance with regard to medications, follow-up, and so forth?

Dr Maniar. I am going to restate it just to make sure I heard it correctly. Is there something that we can identify to improve patient compliance prior to them being discharged?

Dr Arora. Correct, specifically with regard to your discharge planning education processes that you have in place. 
Dr Maniar. Right now we do have a program with regard to patient education that begins 1 to 2 days before discharge. It primarily involves the nursing staff describing to the patients what medications they are receiving and why they are being administered. The question is whether this is fully absorbed by the patient or not.
There are plenty of reports where early intervention or early access to a physician does not decrease the readmission rate, and that again emphasizes the need for a broad enough intervention with a specific target group. So $I$ think it is something that we are going to need to work on, but so far these are just preliminary answers. 